\title{
Preparation and Optimization of PEGylated Nano Graphene Oxide-Based Delivery System for Drugs with Different Molecular Structures Using Design of Experiment (DoE)
}

\author{
Mohammad Hossain Shariare ${ }^{1} \mathbb{D}$, Abdullah-Al Masum ${ }^{1}$, Sultan Alshehri ${ }^{2} \mathbb{D}$, Fars K. Alanazi ${ }^{2}$, Jamal Uddin ${ }^{3} \mathbb{D}$ \\ and Mohsin Kazi ${ }^{2, *(D)}$ \\ 1 Department of Pharmaceutical Sciences, North South University, Dhaka 1229, Bangladesh; \\ mohammad.shariare@northsouth.edu (M.H.S.); abdullah.masum01@northsouth.edu (A.-A.M.) \\ 2 Department of Pharmaceutics, College of Pharmacy, King Saud University, Riyadh 11451, Saudi Arabia; \\ salshehri1@ksu.edu.sa (S.A.); afars@ksu.edu.sa (F.K.A.) \\ 3 Center for Nanotechnology, Department of Natural Sciences, Coppin State University, \\ Baltimore, MD 21216, USA; juddin@coppin.edu \\ * Correspondence: mkazi@ksu.edu.sa
}

check for updates

Citation: Shariare, M.H.; Masum, A.-A.; Alshehri, S.; Alanazi, F.K.; Uddin, J.; Kazi, M. Preparation and Optimization of PEGylated Nano Graphene Oxide-Based Delivery System for Drugs with Different Molecular Structures Using Design of Experiment (DoE). Molecules 2021, 26, 1457. https://doi.org/10.3390/ molecules 26051457

Academic Editor: Anna Petruczynik

Received: 6 February 2021

Accepted: 26 February 2021

Published: 7 March 2021

Publisher's Note: MDPI stays neutral with regard to jurisdictional claims in published maps and institutional affiliations.

Copyright: (c) 2021 by the authors. Licensee MDPI, Basel, Switzerland. This article is an open access article distributed under the terms and conditions of the Creative Commons Attribution (CC BY) license (https:/ / creativecommons.org/licenses/by/ $4.0 /)$.

\begin{abstract}
Graphene oxide (GO), due to its 2D planar structure and favorable physical and chemical properties, has been used in different fields including drug delivery. This study aimed to investigate the impact of different process parameters on the average size of drug-loaded PEGylated nano graphene oxide (NGO-PEG) particles using design of experiment (DoE) and the loading of drugs with different molecular structures on an NGO-PEG-based delivery system. GO was prepared from graphite, processed using a sonication method, and functionalized using PEG 6000. Acetaminophen (AMP), diclofenac (DIC), and methotrexate (MTX) were loaded onto NGO-PEG particles. Drugloaded NGO-PEG was then characterized using dynamic light scattering (DLS), Fourier transform infrared (FTIR), scanning electron microscopy (SEM), differential scanning calorimetry (DSC), XRD. The DLS data showed that the drug-loaded NGO-PEG suspensions were in the size range of $200 \mathrm{~nm}-$ $1.3 \mu \mathrm{m}$. The sonication time and the stirring rate were found to be the major process parameters which affected the average size of the drug-loaded NGO-PEG. FTIR, DSC, XRD, and SEM demonstrated that the functionalization or coating of the NGO occurred through physical interaction using PEG 6000. Methotrexate (MTX), with the highest number of aromatic rings, showed the highest loading efficiency of $95.6 \%$ compared to drugs with fewer aromatic rings (diclofenac (DIC) $70.5 \%$ and acetaminophen (AMP) 65.5\%). This study suggests that GO-based nano delivery systems can be used to deliver drugs with multiple aromatic rings with a low water solubility and targeted delivery (e.g., cancer).
\end{abstract}

Keywords: graphene oxide (GO); nano graphene oxide (NGO); NGO-PEG; aromatic ring; loading efficiency; methotrexate; diclofenac; acetaminophen

\section{Introduction}

The development of nanosystems has attracted much research attention and enjoyed tremendous growth worldwide. Several different types of nanosystems, such as silica nanoparticles [1], liposomes [2], and metal-based and carbon-based nanomaterials [3,4], have been developed since the emergence of nanosystems. Carbon-based nanosystems, carbon nanotubes (CNTs) [5] and graphene or its oxidation derivatives, graphene oxide (GO) [6], are sought after for their physical and chemical properties and have been extensively studied [7,8]. CNTs and GO have some similar behaviors [9] but, in comparison, GO may provide some advantages over CNTs. For example, the toxicity of GO (in vitro) in U251 human glioma cells is lower than that of CNTs [10,11]. The 2D plane structure of GO allows for the loading of microspheres with a diameter larger than several hundred nanometers [12]. The larger surface area of GO improves the interfacial contact and 
prevents aggregation [13,14]. The formation of stable colloidal dispersions in the solvent allows GO to be processed easily [15]. The surface chemistry (functional groups) of GO suggests its polar characteristics, and GO is highly stable owing to the strong covalent bond between its carbon atoms [16,17]. Due to GO's favorable physical and chemical properties, graphene has been extensively studied in different research fields, such as in nanoelectronic devices, sensors, conductors, solar cells, etc. [18]. GO is investigated in biological and biomedical fields due to its biocompatibility along with its excellent physical properties [19-22] for drug delivery [22-25], such as in the delivery of oridonin and methotrexate [26], the delivery of paclitaxel [27], and the delivery of SiRNA [28], etc.

Polyethylene glycol (PEG) possesses a low toxicity and higher solubility in aqueous solutions and has biocompatibility $[29,30]$ and elimination through renal and hepatic routes [30]. The FDA has approved PEG for human use and currently various pharmaceutical formulations of PEG are available. Therefore, PEGylated GO (PEG-GO) is expected to be soluble in biological systems as well as being a safe and stable carrier for the delivery of different types of drugs [31].

Drugs with different molecular structures behave differently during processing. Aromatic ring-containing drugs are most often water insoluble [32], which causes a decrease in the bioavailability of the drugs and worsens the subsequent therapeutic outcomes. Previously, it was reported that the drug loading on GO occurs via $\pi-\pi$ interaction $[13,33-35]$, hence the number of $\pi$ bonds (e.g., aromatic ring) in the drug molecule may enhance the drug loading on GO. Therefore, GO can be a promising carrier for the delivery of an aromatic ring containing insoluble drugs.

In this study, drugs with different molecular structures and properties were investigated during processing with a graphene oxide-based nano-drug delivery system. The impact of the process parameters on the average size of the drug-loaded NGO-PEG particles was investigated using design of experiment (DoE). PEG 6000 was used to functionalize or coat the nano graphene oxide particles through physical interactions instead of chemical processing. The solid-state characterization of drug-loaded NGO-PEG suspensions was performed using scanning electron microscopy (SEM), Fourier transform infrared (FTIR) spectroscopy, differential scanning calorimetry (DSC), and X-ray diffraction (XRD). Furthermore, the percentage of drug loading according to the molecular structure of drugs (aromatic ring number) on the NGO-PEG nanoparticles was also investigated.

\section{Results and Discussion}

\subsection{Particle Size Distribution Analysis and PDI}

It is crucial to measure and control the droplet size of the nanosuspensions to maintain quality and performance. The droplet size could influence the rate and extent of the drug release from the nanosuspensions as well as improve the stability. A higher polydispersity (PDI) value refers to the lower uniformity of the nanosuspension droplet size. The AMPloaded NGO-PEG suspensions prepared in this study were in the range of $200 \mathrm{~nm}$ to $1.3 \mu \mathrm{m}$, which was characterized by the DLS method (Table 1). The largest droplet sizes were observed in batch number four $(1356 \mathrm{~nm})$. with the highest PDI value of 0.88 . The droplet sizes considerably dropped down to $209.10 \mathrm{~nm}$, with the lowest PDI value of 0.18 (monodispersed). However, precipitation was observed for the acetaminophen-loaded GObased nanosuspension batches prepared using the longer stirring time (60 $\mathrm{min})$, therefore the average particle size of these batches was not determined and included in Table 1. It should be noted that the performance of the nanosuspensions is governed by their fate in the gastrointestinal (GI) tract, rather than the particle size of the initial dispersion. 
Table 1. Average particle size of acetaminophen-loaded NGO-PEG suspensions prepared using DoE.

\begin{tabular}{|c|c|c|c|c|c|c|c|}
\hline No. & $\begin{array}{c}\text { NGO } \\
\text { Sonication } \\
\text { Time (hrs) }\end{array}$ & $\begin{array}{l}\text { PEGylation } \\
\text { Sonication } \\
\text { Time (mins) }\end{array}$ & $\begin{array}{c}\text { Stirring } \\
\text { Time (mins) }\end{array}$ & $\begin{array}{l}\text { Stirring Rate } \\
\text { (rpm) }\end{array}$ & $\begin{array}{l}\text { Average Size } \\
(\mathrm{nm})\end{array}$ & $\begin{array}{c}\text { Standard } \\
\text { Deviation (SD) }\end{array}$ & PDI \\
\hline 1 & 2 & 20 & 30 & 1500 & 209.1 & 3.0 & 0.18 \\
\hline 2 & 2 & 20 & 30 & 500 & 1129.0 & 35.4 & 0.76 \\
\hline 3 & 2 & 10 & 30 & 1500 & 880.8 & 31.2 & 0.40 \\
\hline 4 & 2 & 10 & 30 & 500 & 1356.0 & 56.0 & 0.83 \\
\hline 5 & 1 & 20 & 30 & 1500 & 278.3 & 8.3 & 0.37 \\
\hline 6 & 1 & 20 & 30 & 500 & 641.9 & 14.3 & 0.26 \\
\hline 7 & 1 & 10 & 30 & 1500 & 749.9 & 27.8 & 0.63 \\
\hline 8 & 1 & 10 & 30 & 500 & 834.5 & 21.0 & 0.80 \\
\hline
\end{tabular}

\subsection{Effect of Process Parameters on the Average Size of GO Nanoparticles}

The process parameters' PEGylation sonication times and stirring rates were found to have a major impact on the average size of the drug-loaded NGO-PEG particles (Figures 1 and 2). The average particle sizes for the drug-loaded NGO-PEG particles were the lowest (AMP: $240 \pm 5 \mathrm{~nm}$, DIC: $306 \pm 10 \mathrm{~nm}$, MTX: $825 \pm 60 \mathrm{~nm}$ ) when processed at a high level of processing conditions (except stirring time). However, acetaminophen (AMP)-loaded NGO-PEG nanoparticles showed the lowest average size compared to the diclofenac (DIC)- and methotrexate (MTX)-loaded nanoparticles using similar processing conditions. The results suggest that drugs with different molecular structures processed using similar conditions behave differently. This phenomenon is likely related to the brittleness characteristics of acetaminophen compared to other drugs [36]. This phenomenon also may be linked to the different levels of supersaturations generated during the processing of different drugs, leading to the differences in the nucleation rate and the particle size distribution. These results suggest that drugs with different molecular structures and properties will behave differently during processing. The longer duration of sonication exhibited a lower average particle size for nanosuspensions (AMP: $240 \pm 5 \mathrm{~nm}$, DIC: $306 \pm 10 \mathrm{~nm}$ ) compared to the shorter duration of sonication (AMP: $290 \pm 12 \mathrm{~nm}$, DIC: $362 \pm 6 \mathrm{~nm}$ ). Stirring at a high rate resulted in a lower average particle size for the nanosuspensions (AMP: $240 \pm 5 \mathrm{~nm}$, DIC: $306 \pm 10 \mathrm{~nm}$ ) than stirring at a low rate (AMP: $273 \pm 11 \mathrm{~nm}$, DIC: $370 \pm 15 \mathrm{~nm})$.

\section{Main Effects Plot for SIZE \\ Fitted Means}

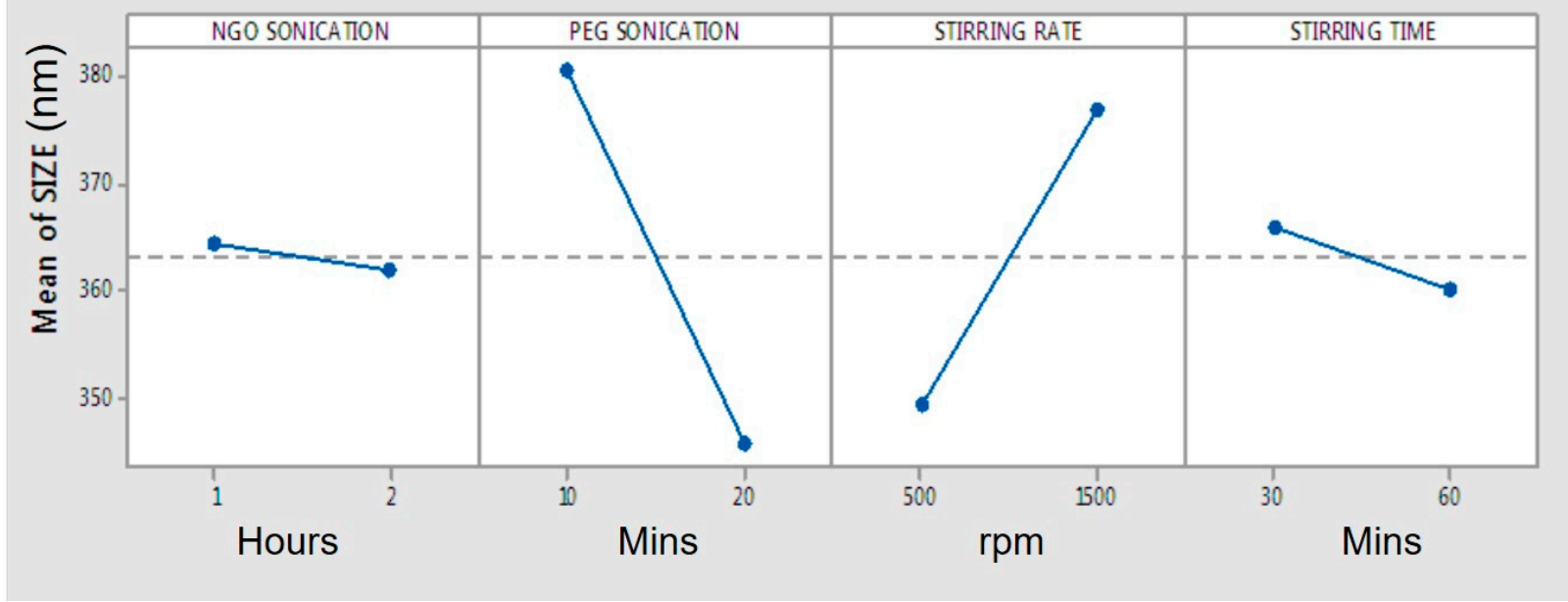

Figure 1. Main effect plots for the impact of process parameters on average particle size. 


\section{Pareto Chart of the Standardized Effects}

(response is SIZE, $\alpha=0.05$ )

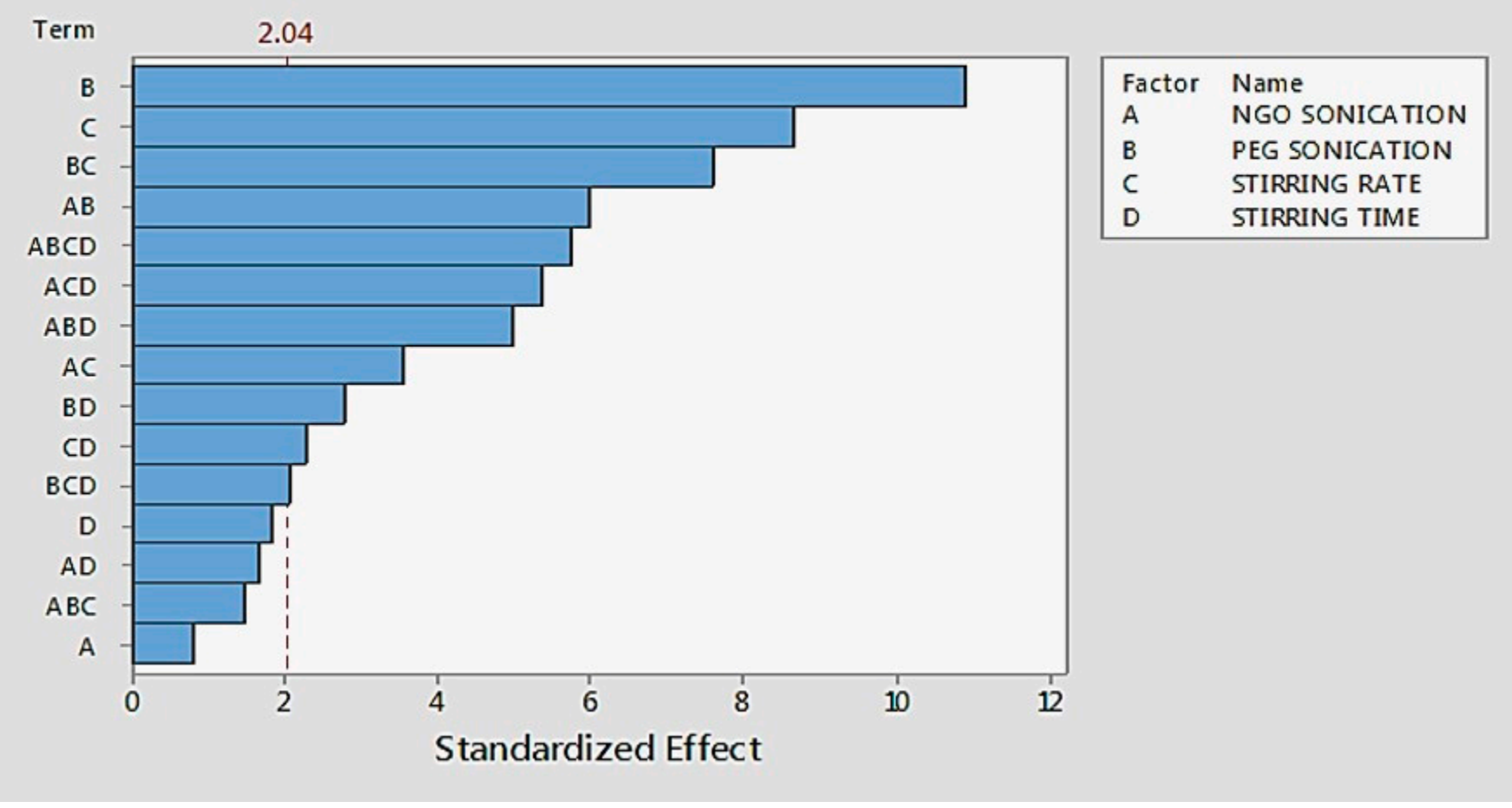

Figure 2. Pareto plot showing the impact of process parameters on the average particle size of the AMP loaded NGOPEG suspension.

\subsection{Drug Loading Efficiency}

The research suggests that drug loading on GO occurs via $\pi-\pi$ interaction [13], and therefore the number of $\pi$ bonds (e.g., aromatic ring) in drug molecules may facilitate drug loading on graphene oxide. As such, three different drugs including AMP, DIC and MTX, with 1,2, and 3 aromatic rings, respectively, were loaded onto NGO-PEG particles. The results shown in Figure 3 suggest that the drug molecule with a greater number of aromatic rings shows higher drug-loading (MTX: $95.6 \pm 4.3 \%$; $14.3 \mathrm{mg}$ ) compared to the drug with fewer aromatic rings (DIC: $70.5 \pm 1.7 \%$; $10.6 \mathrm{mg}$, AMP: $65.5 \pm 1.5 \%$; $9.8 \mathrm{mg}$ ) (Figure 3) [13]. This result suggests that drugs with different molecular structures processed using similar conditions behave differently during loading on the NGO-PEG particles. However. drugs loaded onto non-PEGylated NGO particles showed very low percentages of loading (Figure 3). 

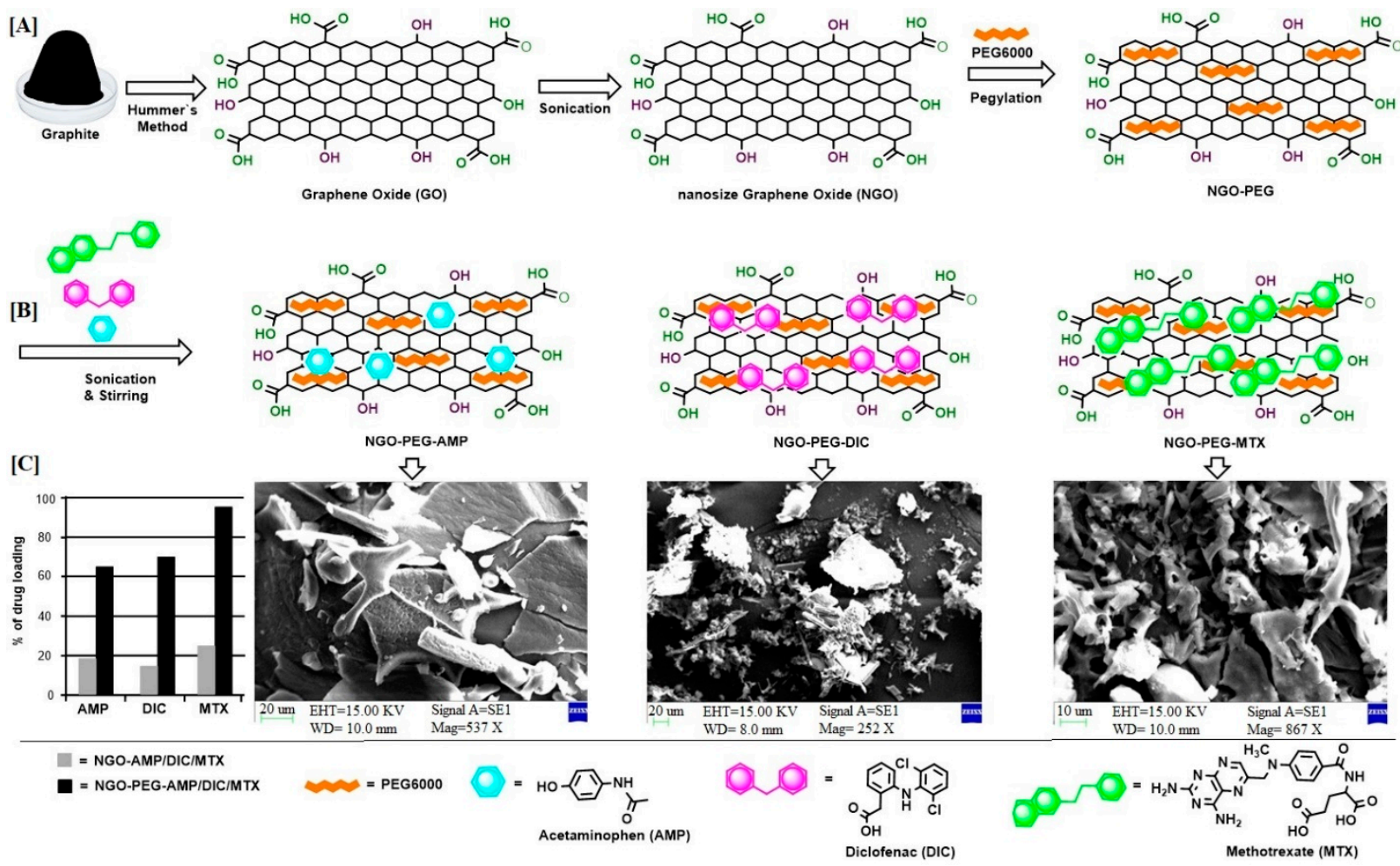

Figure 3. Schematic illustration showing the impact of the molecular structure of the drugs on the drug loading efficiency of NGO-PEG particles: (A) preparation of NGO-PEG, (B) loading of drugs onto NGO-PEG with different numbers of aromatic rings, (C) bar diagram showing the percentage of drug loading and SEM micrographs of drug-loaded NGO-PEG particles.

\subsection{SEM}

The SEM images (Figure 4A-C) show the morphology of GO, NGO, and PEGylated NGO prepared from GO in this study. The NGO was likely functionalized or coated by the PEG 6000 through physical interaction, which was evident from the smooth surface of the PEG-NGO (Figure 4C). The SEM data (Figure 4D-F) also show that three different drugs were loaded onto the NGO-PEG and the highest drug loading was observed for MTX (Figure 4F).

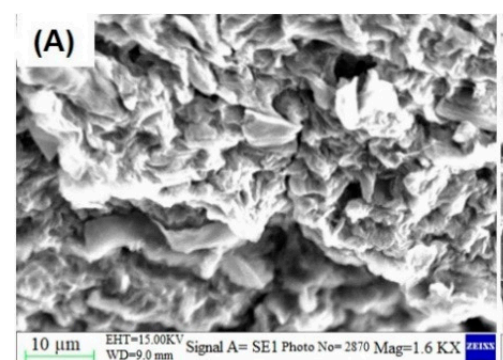

\section{(B)}
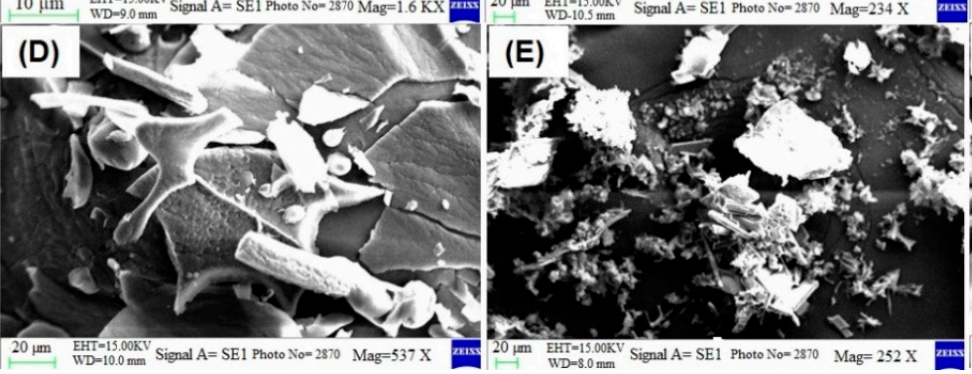

(c)
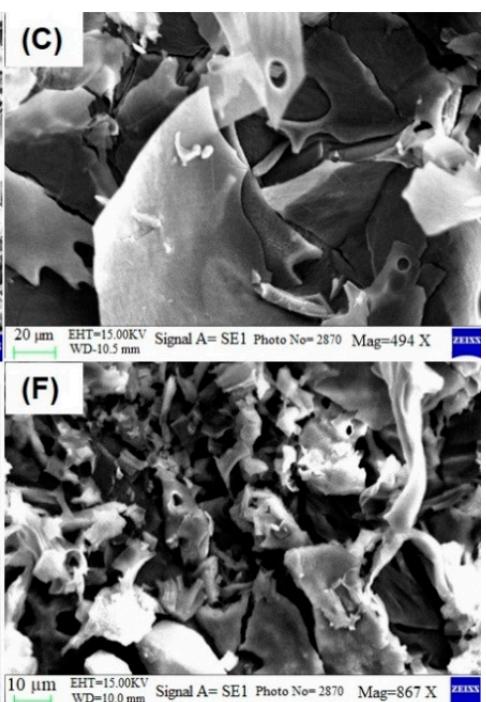

Figure 4. SEM micrographs of (A) GO, (B) NGO, (C) NGO-PEG, (D) AMP-loaded NGO-PEG, (E) diclofenac (DIC)-loaded NGO-PEG, and (F) methotrexate (MTX)-loaded NGO-PEG. 


\subsection{FTIR}

The FTIR spectra of NGO, PEG 6000, and PEGylated NGO are displayed in Figure 5. The FTIR spectrum of NGO (Figure 5A) showed characteristic peaks at $\sim 3400 \mathrm{~cm}^{-1}$ and $\sim 1720 \mathrm{~cm}^{-1}$ for $-\mathrm{OH}$ and the $\mathrm{C}=\mathrm{O}$ functional group, respectively $[37,38]$. The FTIR spectrum of the PEG 6000 (Figure 5B) also showed strong intense bands at the wavenumbers of $\sim 1102 \mathrm{~cm}^{-1}$ (C-O-C stretch), $\sim 2888 \mathrm{~cm}^{-1}$ (C-H stretch), and $\sim 3448 \mathrm{~cm}^{-1}$ (O-H stretch) [39].
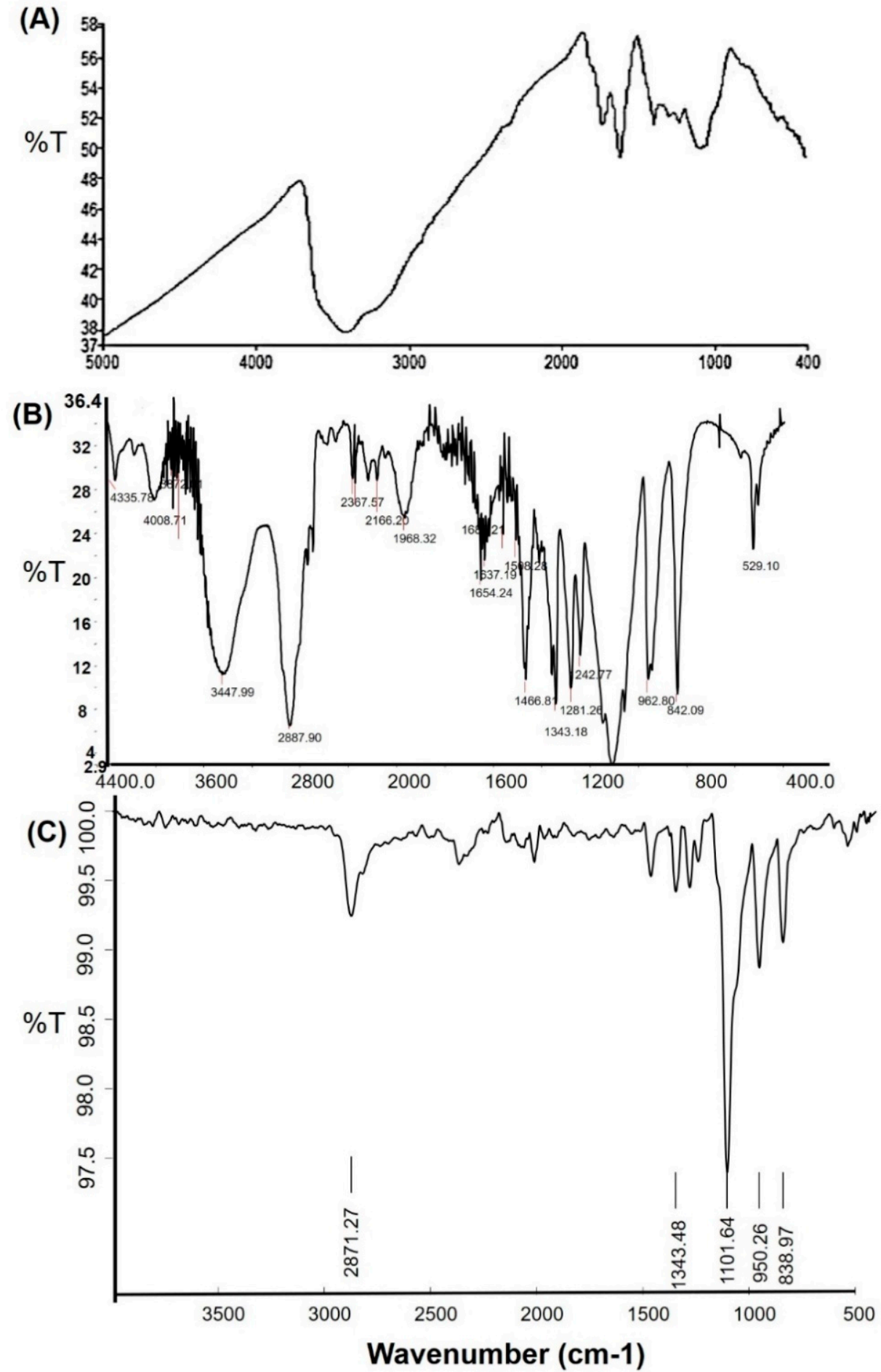

Figure 5. Fourier transform infrared (FTIR) spectra of (A) GO, (B) PEG 6000 and (C) PEGylated NGO. 
Two of these major intense peaks in Figure 5B were also present in Figure 5C for PEGylated NGO at a $\sim 1102 \mathrm{~cm}^{-1}$ (C-O-C stretch), and $\sim 2888 \mathrm{~cm}^{-1}$ (C-H stretch) wavenumber. Therefore, the FTIR data (Figure 5) suggest that the NGO was likely functionalized or coated by PEG 6000 using the sonication method, which was also evident from the SEM micrographs (Figure 4C). GO and PEG 6000 contain many carboxylate and hydroxyl groups. Therefore, these groups were good candidates for forming hydrogen bonds. In addition, PEG 6000 is a commonly used stabilizer which also may take part in van der Waals interactions among GO, drugs and solvents. Therefore, PEG 6000 may have contributed to the activation of GO physically through these interactions.

\subsection{DSC}

The DSC result illustrated in Figure $6 \mathrm{~A}$ showed a sharp exothermic peak at $\sim 200{ }^{\circ} \mathrm{C}$ which was possibly attributed to the reduction of GO (NGO). An exothermic peak for GO at $\sim 196{ }^{\circ} \mathrm{C}$ was also observed by Traina and Pegoretti [40]. PEG 6000 (Figure 6B) showed an endothermic melting transition at $66.7^{\circ} \mathrm{C}$ with $\Delta \mathrm{H}=183.70 \mathrm{~J} / \mathrm{g}$. The DSC thermogram of NGO-PEG (Figure 6C) showed a sharp endothermic peak at $61.74{ }^{\circ} \mathrm{C}$ and a diffuse broad exothermic peak in the range of $170-220^{\circ} \mathrm{C}$ which is probably related to the endothermic melting of PEG 6000 and reduction of GO, respectively [40]. These results suggest that possibly NGO was functionalized by PEG 6000.
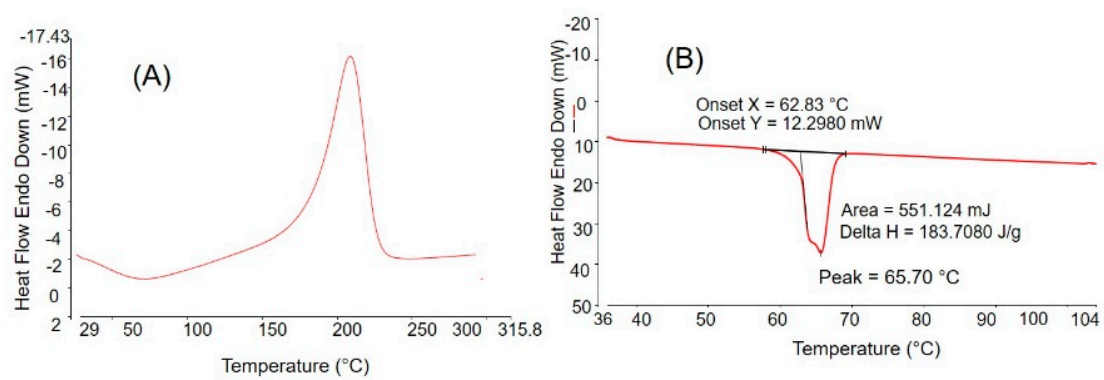

(D)
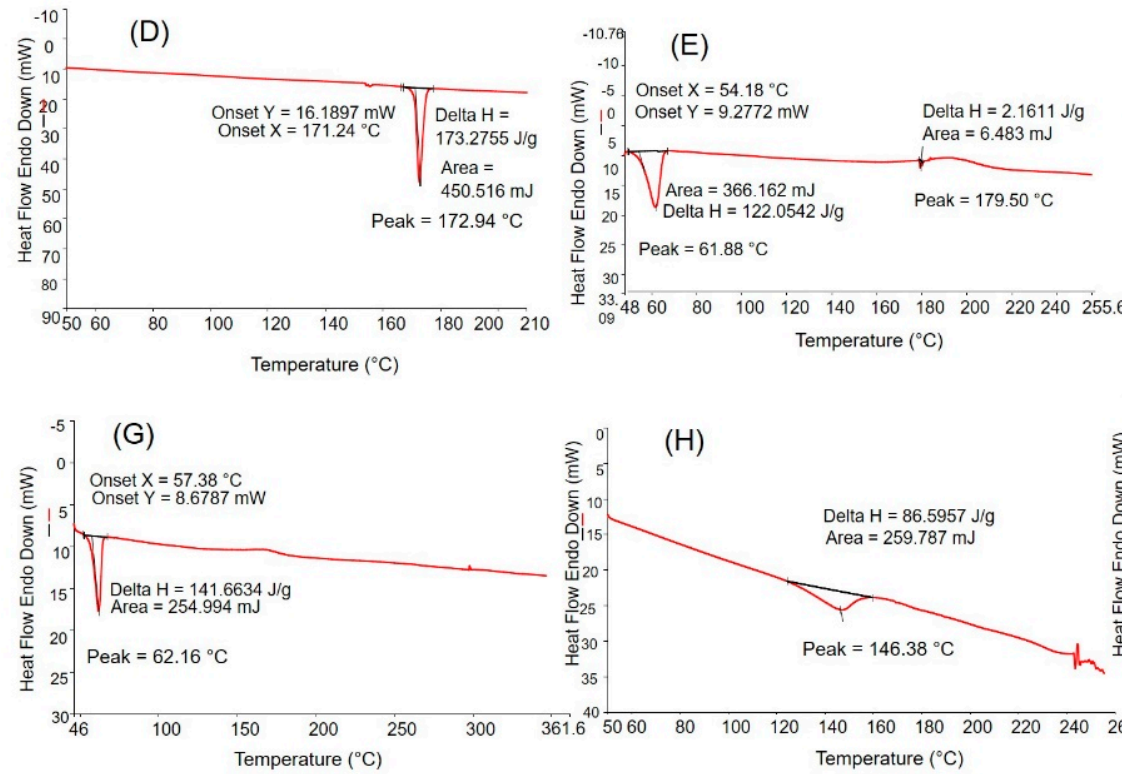

$(\mathrm{H})$

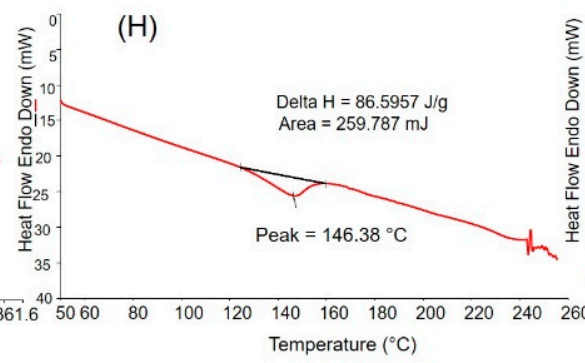

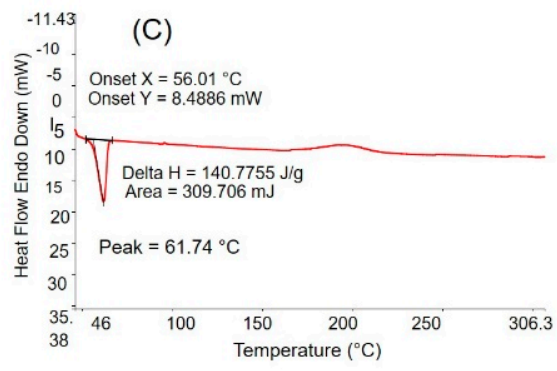

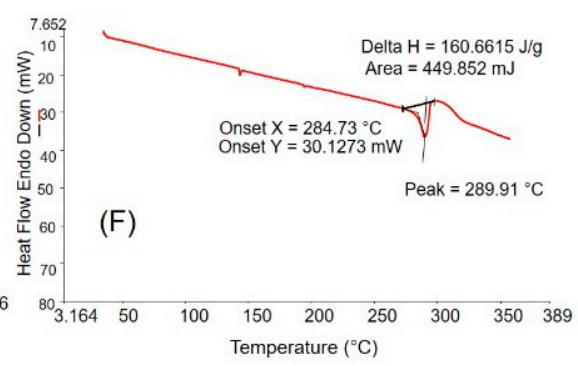

(I)

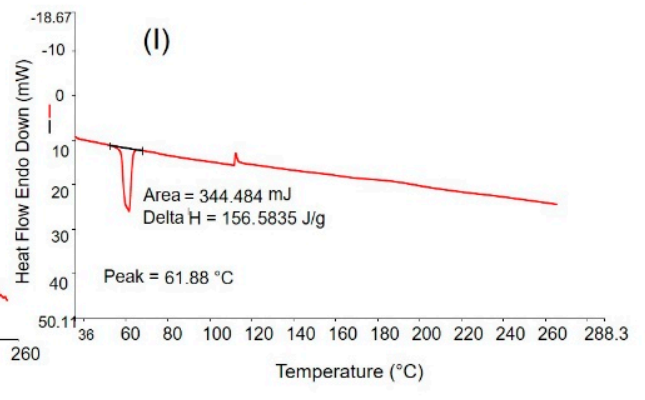

Figure 6. DSC thermograms of (A) NGO, (B) PEG 6000, (C) NGO-PEG, (D) AMP, (E) AMP loaded NGO-PEG, (F) DIC, (G) DIC-loaded NGO-PEG, (H) MTX, and (I) MTX-loaded NGO-PEG.

The DSC thermograms showed strong endothermic melting peaks for all three drugs used in this study (Figure 6D,F,H). The drug-loaded NGO-PEG did not show any endothermic melting peaks for the drugs, except an endothermic melting peak for PEG 6000 at a 
slightly lower temperature $\left(61.8-62.16^{\circ} \mathrm{C}\right)$ compared to the pure PEG 6000. The absence of drug endothermic peaks may indicate that the drugs are dispersed into the NGO-PEG particles mostly or the drugs are likely converted into the amorphous state during processing and loading on the NGO-PEG particles. This phenomenon was also observed in previous studies when PEG 6000 was used in developing solid dispersions of different drugs [41-44].

\subsection{X-ray Diffraction (XRD)}

The X-ray diffraction (XRD) data (Figure 7A) showed a sharp intense peak at a $2 \theta$ value of $\sim 10^{\circ}$ for NGO, which was also observed by other researchers for GO [45,46] with a broad peak in the range of $20-30^{\circ} 2 \theta$, indicating the amorphous nature of the GO while converting into NGO by sonication. Figure 7B shows a crystalline XRD pattern with a sharp, intense peak at around $19.40^{\circ}$ and $23.34^{\circ} 2 \theta$ for PEG 6000. This result also coincides with the XRD pattern observed by Valizadeh et al. for PEG 6000 [46]. The XRD pattern for the functionalized NGO-PEG showed only the major peak of PEG 6000; however, no sharp peak was observed at $2 \theta$ value of $\sim 10^{\circ}$. The DSC result showed similar characteristics for NGO-PEG which indicates that the functionalization or coating of NGO likely has occurred by PEG 6000 . Since $5 \mathrm{mg}$ of PEG 6000 has been used per $\mathrm{mL}$ of the NGO suspension, it is assumed that the PEG 600 might have coated the NGO particles predominantly.

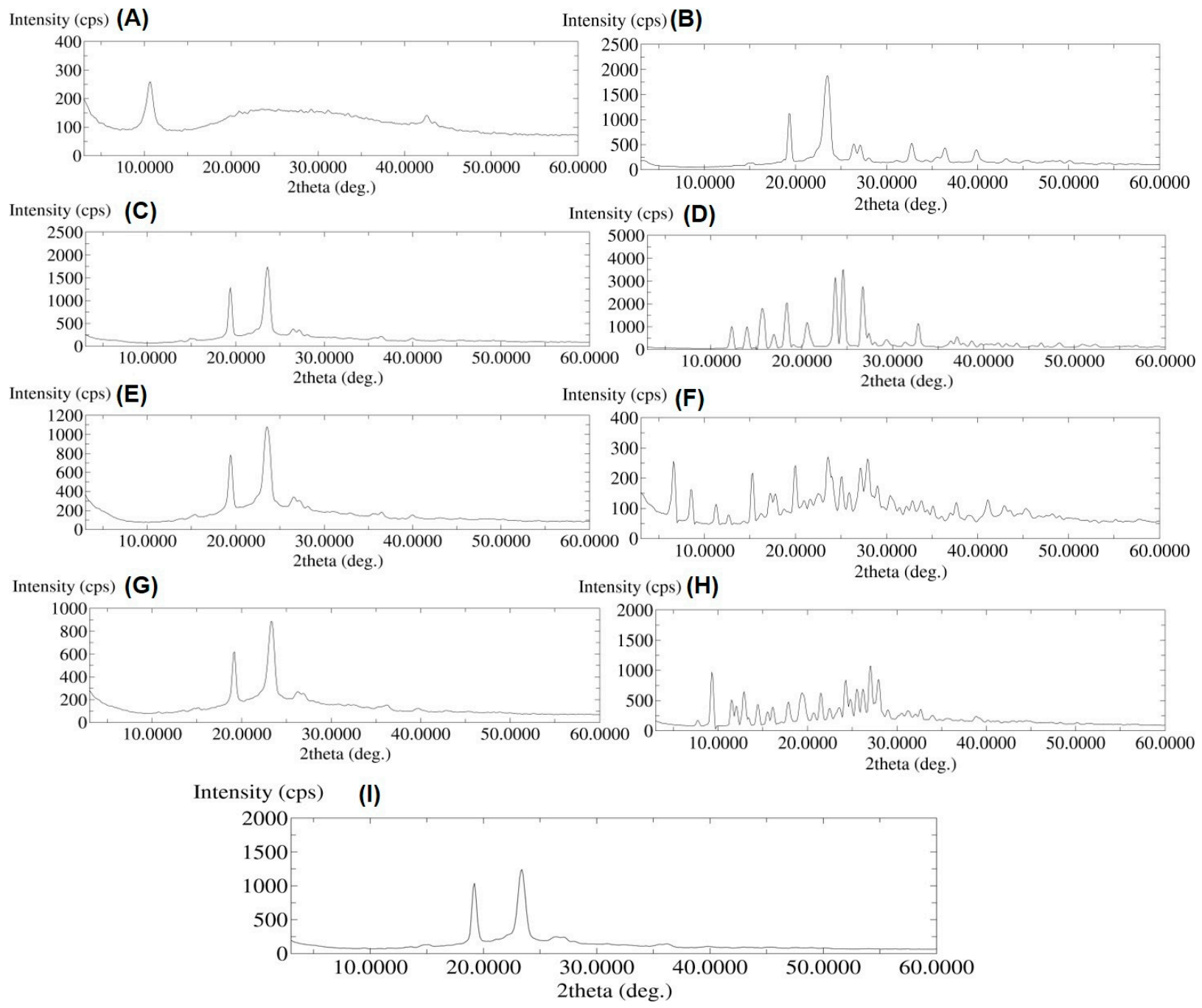

Figure 7. PXRD pattern of (A) NGO, (B) PEG 6000, (C) NGO-PEG, (D) AMP, (E) AMP loaded NGO-PEG, (F) DIC, (G) DIC-loaded NGO-PEG, (H) MTX, and (I) MTX-loaded NGO-PEG. 
This result also suggests that NGO probably was dispersed in the PEG 6000 and exhibited only the major peaks of PEG 6000. Pure AMP, DIC and MTX showed sharp crystalline XRD patterns (Figure 7D,F,H); however, the drug loaded NGO-PEG showed a sharp, intense peak at $19.40^{\circ}$ and $23.34^{\circ} 2 \theta$ only, which are the major peaks for PEG 6000. These results suggest that drugs loaded onto NGO-PEG may be dispersed into PEG 6000 or become amorphous during the preparation process. Therefore, no sharp major peaks for all of the three drugs were observed from the XRD pattern of the drug-loaded NGO-PEG particles.

\section{Materials and Methods}

\subsection{Materials}

Graphite was purchased from Qualikems Fine Chem Pvt. Ltd. (Gujarat, India) with an average particle diameter of 4 micrometers. Sulfuric acid (98\%), ortho phosphoric acid $(85 \%)$, and hydrochloric acid (37\%) were purchased from Merck (Darmstadt, Germany). Potassium permanganate and hydrogen peroxide $(30 \%)$ were purchased from Sigma, (Darmstadt, Germany). Acetaminophen, Diclofenac and PEG 6000 were obtained from the Department of Pharmaceutical Sciences Lab, North South University, (Dhaka, Bangladesh). Methotrexate was provided by Popular Pharmaceuticals Limited, (Dhaka, Bangladesh), as a gift.

\subsection{Methods}

\subsubsection{Preparation of Graphene Oxide (GO)}

Graphene oxide (GO) was prepared by a modified Hummer method [47]. Three grams of graphite and $18 \mathrm{~g}$ of potassium permanganate (1:6 by weight) were thoroughly mixed together in a $1 \mathrm{~L}$ beaker. Subsequently, $360 \mathrm{~mL}$ of $98 \%$ sulphuric acid was poured into a $500 \mathrm{~mL}$ beaker and then $40 \mathrm{~mL}$ of $75 \%$ phosphoric acid (9:1 ratio) was added. The acids were added to the graphite and potassium permanganate mixture while stirring (approximately $50 \mathrm{rpm}$ ) with a glass rod (slowly and in a clockwise motion) at room temperature $\left(25^{\circ} \mathrm{C}\right)$. The mixture was then placed on a hot plate and stirred at $50{ }^{\circ} \mathrm{C}$ for $12 \mathrm{~h}$. The mixture was allowed to cool at room temperature. The ice, prepared using deionized water, was transferred into a large glass container. The graphite acid mixture was then poured over the ice in the large glass container. Three milliliters of $30 \%$ hydrogen peroxide was added to the mixture and stirred to obtain GO. Two liters of tap water was added to the GO mixture and left for two days to settle down. The excess water was then removed and the process was repeated twice. The precipitate was collected and kept in an open beaker so that the remaining water could evaporate at room temperature. The precipitate was then rinsed using $10 \% \mathrm{HCl}$ and deionized water, respectively, and dried in ambient conditions.

\subsubsection{Preparation of NGO Particles}

NGO batches of $50 \mathrm{~mL}$ each with a concentration of $1 \mathrm{mg} / \mathrm{mL}$ were prepared by the sonication method. The amount of GO required for each $50 \mathrm{~mL}$ suspension was calculated from the desired concentrations. Then, the GO was added to $50 \mathrm{~mL}$ of distilled water. This GO suspension was then sonicated using a Cole-Parmer 130-Watt ultrasonic processor $(248 \mathrm{~mm} \times 89 \mathrm{~mm} \times 318 \mathrm{~mm})$ at $80 \%$ amplification. The process was run in ambient conditions $\left(25^{\circ} \mathrm{C}\right.$ temperature) for two hours.

\subsubsection{Preparation of PEGylated NGO}

The NGO suspension was sonicated using a Cole-Parmer 130-Watt ultrasonic processor $(248 \mathrm{~mm} \times 89 \mathrm{~mm} \times 318 \mathrm{~mm})$ with $250 \mathrm{mg}$ of PEG 6000. The process was run in an ambient condition $\left(25^{\circ} \mathrm{C}\right)$ for two hours. Then the suspension was placed into a water bath at $85^{\circ} \mathrm{C}$ for $4 \mathrm{~h}$. Samples were collected from the different batches and analyzed using the dynamic light scattering (DLS) method. 


\subsubsection{Preparation Process of Drug Loaded PEGylated NGO Using Design of Experiment (DoE)}

The $15 \mathrm{~mL}$ suspensions of drugs (acetaminophen, diclofenac, and methotrexate) at a concentration of $1 \mathrm{mg} / \mathrm{mL}$ were prepared using deionized water and then added to $15 \mathrm{~mL}$ of the PEGylated NGO suspension. Next, the whole suspension was stirred using a magnetic stirrer at different stirring rates and for different stirring time periods. The effect of the process parameters (PPs) on the average particle size of the acetaminophen-loaded NGO-PEG particles was evaluated using DoE (Table 2). Each of the factors was studied at two levels (high $=\mathrm{H}$ and low $=\mathrm{L}$ ), where preliminary studies were utilized to identify the parameter range for the detailed study. The factors used for the design of experiment (DoE) in this study were selected based on previous research and a few pilot-scale batch production assessments.

Table 2. Design of experiment (DoE) for the preparation of acetaminophen (AMP)-loaded PEGylated nano graphene oxide (NGO) batches.

\begin{tabular}{ccccc}
\hline Batch & $\begin{array}{c}\text { Sonication Duration } \\
\text { to Produce Nano GO }\end{array}$ & $\begin{array}{c}\text { Sonication Duration } \\
\text { to Produce PEGylated } \\
\text { Nano GO }\end{array}$ & Stirring Rate & Stirring Time \\
\hline 1 & $\mathrm{H}$ & $\mathrm{H}$ & $\mathrm{H}$ & $\mathrm{H}$ \\
2 & $\mathrm{H}$ & $\mathrm{H}$ & $\mathrm{H}$ & $\mathrm{L}$ \\
3 & $\mathrm{H}$ & $\mathrm{H}$ & $\mathrm{L}$ & $\mathrm{L}$ \\
4 & $\mathrm{H}$ & $\mathrm{L}$ & $\mathrm{L}$ \\
5 & $\mathrm{~L}$ & $\mathrm{~L}$ & $\mathrm{~L}$ \\
6 & $\mathrm{~L}$ & $\mathrm{H}$ & $\mathrm{H}$ \\
7 & $\mathrm{~L}$ & $\mathrm{H}$ & $\mathrm{H}$ \\
8 & $\mathrm{~L}$ & $\mathrm{H}$ & $\mathrm{H}$ \\
9 & $\mathrm{H}$ & $\mathrm{H}$ & $\mathrm{H}$ \\
10 & $\mathrm{~L}$ & $\mathrm{~L}$ & $\mathrm{~L}$ \\
11 & $\mathrm{H}$ & $\mathrm{L}$ & $\mathrm{H}$ \\
12 & $\mathrm{~L}$ & $\mathrm{H}$ & $\mathrm{H}$ \\
14 & $\mathrm{~L}$ & $\mathrm{H}$ & $\mathrm{L}$ \\
15 & $\mathrm{H}$ & $\mathrm{H}$ & $\mathrm{L}$ & $\mathrm{H}$ \\
& $\mathrm{H}$ & $\mathrm{L}$ & $\mathrm{L}$ \\
\hline
\end{tabular}

A full factorial experimental design (Table 2) implementing four process parameters was used. The four process parameters included: (1) the sonication time to produce nano graphene oxide; (2) the sonication time to prepare PEGylated nano graphene oxide; (3) the rate of stirring at which the drug is incorporated in the PEGylated nano graphene oxide; and (4) the duration of stirring of the drug and PEGylated nano graphene oxide at two levels, high and low, using acetaminophen as a drug (Table 2). The high and low values of the four process parameters are as follows: the duration of sonication to produce NGO (high $=2 \mathrm{~h}$; low $=1 \mathrm{~h}$ ), the duration of sonication for PEGylated NGO (high $=20 \mathrm{~min}$; low $=10 \mathrm{~min}$ ), the stirring rate (high $=1500 \mathrm{rpm}$; low $=500 \mathrm{rpm}$ ), and the stirring time (high $=60 \mathrm{~min}$; low $=30 \mathrm{~min}$ ). The PEGylated nanographene oxide-based delivery of other drugs (diclofenac and methotrexate) was prepared using optimized conditions found after the experimental design study.

\subsubsection{Drug Loading Efficiency}

Percentages of drug loading for graphene oxide-based nano suspensions were sampled in eppendorf tubes and centrifuged at $9800 \times g$ for $30 \mathrm{~min}$ to separate the unbound drug from the drug-loaded NGO-PEG. Both the precipitate and the supernatant were analyzed using UV spectroscopy to determine the concentrations of the bound and unbound drugs, respectively. The UV tests were performed for acetaminophen at $243 \mathrm{~nm}$, diclofenac at $340 \mathrm{~nm}$, and methotrexate at $303 \mathrm{~nm}$. The calibration curve equation and correlation of 
coefficient values are: for acetaminophen, $y=0.0693 x+0.0789, r^{2}=0.996$; for diclofenac, $\mathrm{y}=0.0074 \mathrm{x}+0.125, \mathrm{r}^{2}=0.992$; and for methotrexate, $\mathrm{y}=0.086 \mathrm{x}+0.002, \mathrm{r}^{2}=0.998$. Five different concentrations were used for all three of the different drugs to make the calibration curve, which are $5,10,15,20$, and $25 \mu \mathrm{g} / \mathrm{mL}$.

3.2.6. Particle Size Analysis and Determination of Polydispersity Index (PDI) by Dynamic Light Scattering (DLS)

The particle size distribution and PDI of all the representative graphene oxide (GO)based nano preparations were determined by the dynamic light scattering (DLS) method using the Malvern Zetasizer Nano-ZS (Malvern Instruments, UK) at a $90^{\circ}$ scattering angle. The nanosuspensions were diluted at a ratio of 1:100 $v / v$ (nanosuspensions: deionized water) and mixed for 1 min using a VM1 vortex mixer (Boronia, Australia) before the analysis at $25{ }^{\circ} \mathrm{C}$. The analysis was performed in triplicate and the average value was calculated from the data collected 10 times in the study.

\subsubsection{Scanning Electron Microscopy (SEM)}

The graphene oxide (GO)-based nano preparations were visualized using a (Carl Zeiss AG, Jena, Germany) scanning electron microscope (SEM). The samples were analyzed at a variety of magnifications and captured in high-resolution images onto a personal computer. The samples were distributed onto double-sided adhesive carbon tapes, which were attached to SEM specimen mounts. The specimens were sputter-coated by a Jeol JFC-1600 auto fine coater for $2 \mathrm{~min}$.

\subsubsection{Fourier Transform Infrared (FTIR) Spectroscopy}

An FTIR analysis was conducted to examine possible interactions present between GO and GO-based nano preparations. The chemical properties were obtained and the complexation of the powdered lyophilized samples was performed using the FTIR Spectrum BX from Perkin Elmer LLC (Hopkinton, MA, USA). Pure GO and graphene oxide-based nano preparations (solid powders) were compressed for $5 \mathrm{~min}$ at 5 bars on a $\mathrm{KBr}$ press and the spectra were scanned on the wavenumber range of $400-4000 \mathrm{~cm}^{-1}$.

\subsubsection{Differential Scanning Calorimetry (DSC)}

The thermal characteristics of the powdered samples of NGO, PEG 6000, NGO-PEG, pure drugs, and freeze-dried nanosuspensions of drug-loaded NGO-PEG were characterized by DSC (DSC-60, Shimadzu, Kyoto, Japan). Samples (2-5 mg) were hermetically sealed in aluminum sample pans and heated at a scanning rate of $10^{\circ} \mathrm{C} / \mathrm{min}$ over a temperature range of $25-360^{\circ} \mathrm{C}$. All the samples were analyzed in triplicate and the temperature scale was calibrated using a pure indium standard (melting point of $156.6^{\circ} \mathrm{C}$ ).

\subsubsection{X-ray Diffraction (XRD)}

The X-ray diffraction (XRD) was used to characterize the solid-state form of NGO, PEG 6000, NGO-PEG, pure drugs, and freeze-dried nanosuspensions of drug loaded NGO-PEG using a Rigaku multiflex diffractometer (Rigaku Corporation, Tokyo, Japan). The X-ray source was Ni filtered $\mathrm{CuK}$-alpha radiation (wavelength $1.5418 \mathrm{~A}$ ). The $\mathrm{X}$-ray tube was run at a power of $40 \mathrm{kV}, 40 \mathrm{~mA}$. The analyses were performed over a $2 \theta$ range of $3-60^{\circ}$ with an angular increment of $0.50 \% \mathrm{~min}$ and a scan step time of $1.0 \mathrm{~s}$.

\section{Conclusions}

The results of this study suggest that drugs with different molecular structures processed using similar conditions behave differently in terms of average particle size and loading efficiency on NGO-PEG particles. The NGO-PEG suspension processed with AMP showed the lowest average particle size compared to DIC and MTX, which is probably related to the molecular structure and, more specifically, the different properties (solubility, mechanical behavior) of different solids (drugs). The DoE study results suggest that PEGy- 
lation sonication time and stirring rate are two major parameters which proved to have a marked impact on the average particle size of the drug-loaded NGO-PEG. This result also suggests that PEGylation sonication time should be increased ( $>20 \mathrm{~min}$ ) to achieve NGO-PEG particles with an average size of around $100 \mathrm{~nm}$, which indicates the advantage of using DoE during the processing of NGO-PEG particles. The molecular structure of the drugs, particularly the number of aromatic rings present in the structure, affects the drug loading on NGO-PEG. MTX with three aromatic rings exhibited the highest loading on NGO-PEG particles compared to drugs with fewer aromatic rings, which was also evident in the SEM micrographs. The FTIR, DSC, and XRD data suggest that functionalization or the coating of NGO was performed using PEG 6000, which also suggests that the drugs were dispersed into PEG 6000 or became amorphous when loaded onto NGO-PEG particles during processing. PEGylation of NGO by physical interactions offers a simple and less time-consuming process for developing a functionalized NGO-PEG based drug delivery system. This study also suggests that a GO-based nano drug delivery system can be used as a promising carrier for the delivery of an aromatic ring containing insoluble drugs.

Author Contributions: Conceptualization, M.H.S. Data curation, A.-A.M.; Formal analysis, A.-A.M.; Funding acquisition, M.K.; Investigation, M.H.S.; Methodology, M.H.S. and S.A.; Project administration, F.K.A.; Supervision, M.K.; Visualization, J.U.; Writing—original draft, M.H.S.; Writing—review and editing, S.A., F.K.A., J.U. and M.K. All authors have read and agreed to the published version of the manuscript.

Funding: This research was funded by the Deanship of Scientific Research at King Saud University (RG no 1435-017).

Data Availability Statement: Not applicable.

Acknowledgments: The authors would like to extend their sincere appreciation to the Deanship of Scientific Research at King Saud University for its funding through research group number (RG\#1435-017).

Conflicts of Interest: The authors declare no competing interests in the current studies.

Sample Availability: Samples of the compounds are not available from the authors.

\section{References}

1. Tarn, D.; Ashley, C.E.; Xue, M.; Carnes, E.C.; Zink, J.I.; Brinker, C.J. Mesoporous silica nanoparticle nanocarriers: Biofunctionality and biocompatibility. Acc. Chem. Res. 2013, 46, 792-801. [CrossRef] [PubMed]

2. Schwendener, R.A. Liposomes in Biology and Medicine, in Bio-applications of Nanoparticles. In Advances in Experimental Medicine and Biology; Springer: New York, NY, USA, 2017.

3. Yin, F.; Yang, C.; Wang, Q.; Zeng, S.; Hu, R.; Lin, G.; Tian, J.; Hu, S.; Lan, R.F.; Yoon, H.S.; et al. A light-driven therapy of pancreatic adenocarcinoma using gold nanorods-based nanocarriers for co-delivery of doxorubicin and siRNA. Theranostics 2015, 5, 818-833. [CrossRef]

4. Bekyarova, E.; Ni, Y.; Malarkey, E.B.; Montana, V.; McWilliams, J.L.; Haddon, R.C.; Parpura, V. Applications of carbon nanotubes in biotechnology and biomedicine. J. Biomed. Nanotechnol. 2005, 1, 3-17. [CrossRef]

5. Iijima, S. Helical microtubules of graphitic carbon. Nature 1991, 354, 56-58. [CrossRef]

6. Novoselov, K.S.; Geim, A.K.; Morozov, S.V.; Jiang, D.; Zhang, Y.; Dubonos, S.V.; Grigorieva, I.V.; Firsov, A.A. Electric field effect in atomically thin carbon films. Science 2004, 306, 666-669. [CrossRef] [PubMed]

7. Ando, Y. Carbon nanotube: The inside story. J. Nanosci. Nanotechnol. 2010, 10, 3726-3738. [CrossRef]

8. Loh, K.P.; Bao, Q.; Eda, G.; Chhowalla, M. Graphene oxide as a chemically tunable platform for optical applications. Nat. Chem. 2010, 2, 1015. [CrossRef] [PubMed]

9. Bai, S.; Shen, X. Graphene-inorganic nanocomposites. RSC Adv. 2012, 2, 64-98. [CrossRef]

10. Markovic, Z.M.; Harhaji-Trajkovic, L.M.; Todorovic-Markovic, B.M.; Kepić, D.P.; Arsikin, K.M.; Jovanović, S.P.; Pantovic, A.C.; Dramićanin, M.D.; Trajkovic, V.S. In vitro comparison of the photothermal anticancer activity of graphene nanoparticles and carbon nanotubes. Biomaterials 2011, 32, 1121-1129. [CrossRef] [PubMed]

11. Liu, Z.; Robinson, J.T.; Sun, X.; Dai, H. PEGylated nanographene oxide for delivery of water-insoluble cancer drugs. J. Am. Chem. Soc. 2008, 130, 10876-10877. [CrossRef]

12. Zhou, K.; Zhu, Y.; Yang, X.; Li, C. One-pot preparation of graphene $/ \mathrm{Fe}_{3} \mathrm{O}_{4}$ composites by a solvothermal reaction. New J. Chem. 2010, 34, 2950-2955. [CrossRef] 
13. Pan, Y.; Sahoo, N.G.; Li, L. The application of graphene oxide in drug delivery. Expert Opin. Drug Deliv. 2012, 9, 1365-1376. [CrossRef] [PubMed]

14. Jin, Z.; Nackashi, D.; Lu, W.; Kittrell, C.; Tour, J.M. Decoration, migration, and aggregation of palladium nanoparticles on graphene sheets. Chem. Mater. 2010, 22, 5695-5699. [CrossRef]

15. Yu, S.; Wang, X.; Yao, W.; Wang, J.; Ji, Y.; Ai, Y.; Alsaedi, A.; Hayat, T.; Wang, X. Macroscopic, spectroscopic, and theoretical investigation for the interaction of phenol and naphthol on reduced graphene oxide. Env. Sci. Technol. 2017, 51, 3278-3286. [CrossRef]

16. Li, C.; Wang, X.; Chen, F.; Zhang, C.; Zhi, X.; Wang, K.; Cui, D. The antifungal activity of graphene oxide-silver nanocomposites. Biomaterials 2013, 34, 3882-3890. [CrossRef]

17. Sanchez, V.C.; Jachak, A.; Hurt, R.H.; Kane, A.B. Biological interactions of graphene-family nanomaterials: An interdisciplinary review. Chem. Res. Toxicol. 2012, 25, 15-34. [CrossRef]

18. Das, S.; Sudhagar, P.; Kang, Y.S.; Choi, W. Graphene synthesis and application for solar cells. J. Mater. Res. Technol. 2014, 29, 299-319. [CrossRef]

19. Xu, X.; Zhang, Z.; Qiu, L.; Zhuang, J.; Zhang, L.; Wang, H.; Liao, C.; Song, H.; Qiao, R.; Gao, P. Ultrafast growth of single-crystal graphene assisted by a continuous oxygen supply. Nat. Nanotechnol. 2016, 11, 930-935. [CrossRef] [PubMed]

20. Zhang, X.; Deng, L.; Huang, C.; Zhang, J.; Hou, X.; Wu, P.; Liu, J. Frontispiece: Photosensitization of molecular oxygen on graphene oxide for ultrasensitive signal amplification. Chem. Eur. J. Chem. 2018, 24, 2602-2608. [CrossRef] [PubMed]

21. Cao, T.; You, P.; Zhou, X.; Luo, J.; Xu, X.; Zhou, Z.; Yang, S.; Zhang, Y.; Yang, H.; Wang, M. Visualization of size-dependent tumour retention of PEGylated nanographene oxide via SPECT imaging. J. Mater. Chem. B 2016, 4, 6446-6453. [CrossRef]

22. Tu, Z.; Achazi, K.; Schulz, A.; Mülhaupt, R.; Thierbach, S.; Rühl, E.; Adeli, M.; Haag, R. Combination of surface charge and size controls the cellular uptake of functionalized graphene sheets. Adv. Funct. Mater. 2017, 27, 1701837. [CrossRef]

23. Reina, G.; González-Domínguez, J.M.; Criado, A.; Vázquez, E.; Bianco, A.; Prato, M. Promises, facts and challenges for graphene in biomedical applications. Chem. Soc. Rev. 2017, 46, 4400-4416. [CrossRef]

24. Bitounis, D.; Ali-Boucetta, H.; Hong, B.H.; Min, D.H.; Kostarelos, K. Prospects and challenges of graphene in biomedical applications. Adv. Mater. 2013, 25, 2258-2268. [CrossRef]

25. Cheng, S.-J.; Chiu, H.-Y.; Kumar, P.V.; Hsieh, K.Y.; Yang, J.-W.; Lin, Y.-R.; Shen, Y.-C.; Chen, G.-Y. Simultaneous drug delivery and cellular imaging using graphene oxide. Biomater. Sci. 2018, 6, 813-819. [CrossRef] [PubMed]

26. Chai, D.; Hao, B.; Hu, R.; Zhang, F.; Yan, J.; Sun, Y.; Huang, X.; Zhang, Q.; Jiang, H. Delivery of oridonin and methotrexate via PEGylated graphene oxide. ACS Appl. Mater. Interfaces 2019, 11, 22915-22924. [CrossRef]

27. Xu, Z.; Zhu, S.; Wang, M.; Li, Y.; Shi, P.; Huang, X. Delivery of paclitaxel using PEGylated graphene oxide as a nanocarrier. Acs Appl. Mater. Interfaces 2015, 7, 1355-1363. [CrossRef]

28. Turecek, P.L.; Bossard, M.J.; Schoetens, F.; Ivens, I.A. PEGylation of biopharmaceuticals: A review of chemistry and nonclinical safety information of approved drugs. J. Pharm. Sci. 2016, 105, 460-475. [CrossRef]

29. Ibrahim, K.; Starck, P.; Löfgren, B.; Seppälä, J. Synthesis and characterization of amphiphilic triblock copolymers by iron-mediated atom transfer radical polymerization. J. Polym. Sci. Part A Polym. Chem. 2005, 43, 5049-5061. [CrossRef]

30. Hooftman, G.; Herman, S.; Schacht, E. Poly (ethylene glycol) s with reactive endgroups. II. Practical consideration for the preparation of protein-PEG conjugates. J. Bioact. Compat. Polym. 1996, 11, 135-159.

31. Liu, Y.; Yu, D.; Zeng, C.; Miao, Z.; Dai, L. Biocompatible graphene oxide-based glucose biosensors. Langmuir 2010, 26, 6158-6160. [CrossRef]

32. Rahmanian, N.; Hamishehkar, H.; Dolatabadi, J.E.N.; Arsalani, N. Nano graphene oxide: A novel carrier for oral delivery of flavonoids. Colloids Surf. B 2014, 123, 331-338. [CrossRef] [PubMed]

33. Yu, S.; Wang, X.; Ai, Y.; Tan, X.; Hayat, T.; Hu, W.; Wang, X. Experimental and theoretical studies on competitive adsorption of aromatic compounds on reduced graphene oxides. J. Mater. Chem. A 2016, 4, 5654-5662. [CrossRef]

34. Tang, H.; Zhao, Y.; Shan, S.; Yang, X.; Liu, D.; Cui, F.; Xing, B. Theoretical insight into the adsorption of aromatic compounds on graphene oxide. Environ. Sci. Nano 2018, 5, 2357-2367. [CrossRef]

35. Rochefort, A.; Wuest, J.D. Interaction of substituted aromatic compounds with graphene. Langmuir 2009, 25, 210-215. [CrossRef] [PubMed]

36. Shariare, M.H.; Leusen, F.J.J.; de Matas, M.; York, P.; Anwar, J. Prediction of the mechanical behaviour of crystalline solids. Pharm. Res. 2012, 29, 319-331. [CrossRef]

37. Szabó, T.; Berkesi, O.; Forgó, P.; Josepovits, K.; Sanakis, Y.; Petridis, D.; Dékány, I. Evolution of surface functional groups in a series of progressively oxidized graphite oxides. Chem. Mater. 2006, 18, 2740-2749. [CrossRef]

38. Sun, X.; Liu, Z.; Welsher, K.; Robinson, J.T.; Goodwin, A.; Zaric, S.; Dai, H. Nano-graphene oxide for cellular imaging and drug delivery. Nano Res. 2008, 1, 203-212. [CrossRef]

39. Patil, M.P.; Gaikwad, N.J. Characterization of gliclazide-polyethylene glycol solid dispersion and its effect on dissolution. Braz. J. Pharm. Sci. 2011, 47, 161-166.

40. Traina, M.; Pegoretti, A. In situ reduction of graphene oxide dispersed in a polymer matrix. J. Nanopart. Res. 2012, $14,801$. [CrossRef]

41. Biswal, S.; Sahoo, J.; Murthy, P.N.; Giradkar, R.P.; Avari, J.G. Enhancement of dissolution rate of gliclazide using solid dispersions with polyethylene glycol 6000. Aaps Pharmscitech 2008, 9, 563-570. [CrossRef] 
42. Doshi, D.H.; Ravis, W.R.; Betageri, G.V. Carbamazepine and polyethylene glycol solid dispersions: Preparation, in vitro dissolution, and characterization. Drug Dev. Ind. Pharm. 1997, 23, 1167-1176. [CrossRef]

43. Shin, S.-C.; Kim, J. Physicochemical characterization of solid dispersion of furosemide with TPGS. Int. J. Pharm. 2003, 251, 79-84. [CrossRef]

44. Damian, F.; Blaton, N.; Naesens, L.; Balzarini, J.; Kinget, R.; Augustijns, P.; Van den Mooter, G. Physicochemical characterization of solid dispersions of the antiviral agent UC-781 with polyethylene glycol 6000 and Gelucire 44/14. Eur. J. Pharm. Sci. 2000, 10, 311-322. [CrossRef]

45. Nakajima, T.; Mabuchi, A.; Hagiwara, R. A new structure model of graphite oxide. Carbon 1988, 26, 357-361. [CrossRef]

46. Valizadeh, H.; Nokhodchi, A.; Qarakhani, N.; Zakeri-Milani, P.; Azarmi, S.; Hassanzadeh, D.; Löbenberg, R. Physicochemical characterization of solid dispersions of indomethacin with PEG 6000, Myrj 52, Lactose, Sorbitol, Dextrin, and Eudragit ${ }^{\circledR}$ E100. Drug Dev. Ind. Pharm. 2004, 30, 303-317. [CrossRef] [PubMed]

47. Kusrini, E.; Suhrowati, A.; Usman, A.; Degirmenci, V.; Khalil, M. Synthesis and characterization of graphite oxide, graphene oxide and reduced graphene oxide from graphite waste using modified Hummers's method and zinc as reducing agent. Int. J. Technol. 2019, 10, 1093. [CrossRef] 